\title{
The Rise of Consumer Culture in a Chinese Society: A Reading of Banking Television Commercials in Hong Kong During the 1970 s
}

\author{
Wendy Siuyi Wong \\ Department of Communication Studies \\ Hong Kong Baptist University
}

In this article, I analyze 2 case studies of television advertising campaigns for banking services during the 1970s and early 1980s in Hong Kong, those of Hang Seng Bank and HongkongBank. Advertising from this period saw consumer society emerge as traditional values and themes were adjusted to fit the imperatives of capitalism. The earlier Hang Seng Bank campaign focused on the traditional banking practice of saving, encouraging customers to work hard and gradually accumulate wealth. The later HongkongBank campaign encouraged spending, immediate gratification of material desires, and symbolic status achieved through acquisition of goods. As the case studies show, this process entailed the reconfiguration of traditional Chinese values to accommodate the arrival of consumerism in Hong Kong, a Chinese society.

The consumer society arises out of the ashes of traditional culture, which are characterized by relatively fixed forms for the satisfaction of needs .... The consumer society does not set up its own fixed models of behavior to replace traditional ones but rather constructs, through marketing and advertising, successive waves of associations between persons, products, and images of well-being in an endless series of suggestions about the possible routes to happiness and success.

—Leiss, Kline, and Jhally (1990, p. 287)

Requests for reprints should be sent to Wendy Siuyi Wong, Department of Communication Studies, Hong Kong Baptist University, Kowloon Tong, Kowloon, Hong Kong. E-mail: wsywong@yahoo.com 
The functions of advertising have been understood from a number of theoretical perspectives, which range from a focus on the "justifiable goal" of providing consumers with information of "social value" (Sandage, 1972/1989, p. 6) to Marxist understandings that emphasize ideological functions such as the creation of a commodity-self and the promotion of a consumption-based society through advertising (Ewen, 1976). Examining two television advertising campaigns for the banking services of Hang Seng Bank (HSB) and HongkongBank (HKB) during the 1970s and early 1980s in Hong Kong, I show how economic and cultural shifts in Hong Kong were reflected at the discursive level. I argue that the development of consumer culture in Hong Kong required the modification of many traditional Chinese values. This article demonstrates how specific advertisements reflect changes toward values that integrate global trends in the banking business and are more amenable to consumerism. Because Hong Kong was the first Chinese society to experience a full and direct encounter with consumerism from the West, this study reveals the terms of the initial adjustment of Chinese values and ideals in response to consumer imperatives.

\section{ADVERTISING DISCOURSE, CONSUMER CULTURE, AND SOCIAL CHANGE}

The position here is between a strictly Marxist stance viewing advertising as a form of ideological and social control used by elites to manipulate the masses and a classical liberal position supporting the argument that advertising is a social good because "it is a proper and justifiable social goal to help consumers maximize their satisfaction" (Sandage, 1972/1989, p. 6). Critical scholars such as Ewen (1976) observed that to survive in a healthy form, capitalism must increase production and consumption, and advertising is arguably the fundamental means of doing this, through the "creation of desires and habits" (p. 37). Along these lines, Leiss et al. (1990) perceived that advertising functions to "appropriate and transform a vast range of symbols and ideas" (p. 5). Like their work, this article is based on the idea that advertising is a privileged discourse that appropriates, recirculates, and modifies cultural symbols.

This article focuses specifically on Hong Kong advertising as a means of exploring Hong Kong culture and history. It takes a cultural studies position, with advertising as the information system on which consumption is based (Slater, 1997) and that influences consumer needs and habits by conveying messages communicating meaning, values, and ideology. Bocock (1993) emphasized this role of advertising in furthering consumption:

Modern consumerism ... depends upon its specific set of values becoming acceptable and comprehensible among sufficient groups of people so that sales of consumer 
products can be made. These consumption-oriented values have to include those which either allow, or actively encourage, the purchase of the goods and experiences on offer. (p. 54)

The close textual analysis undertaken here reinforces the idea that the imperatives of advertising in terms of its ideological functions will be to a large extent the same no matter what culture, society, or country they are placed into. This study of the development of banking advertising provides an excellent example of this phenomenon. In its comparative examination of two banking advertisement campaigns, this article examines how the consumer society of Hong Kong arose "out of the ashes of traditional culture" (Leiss et al., 1990, p. 287), with traditional attitudes favoring personal sacrifice, hard work, and savings replaced or transformed into an emphasis on borrowing, consumption, and immediate gratification. This process can be seen as part of a larger process of globalization of consumer culture, founded on the insights that "people's attitudes about their finances are related to their education, and their values, not ... their nationalities" (Barnet \& Cavanagh, 1994, p. 376) and that such attitudes can be influenced in any part of the world by advertising and expanded banking services that encourage spending and debt.

Barnet and Cavanagh (1994) offered a rich detailed history of the rise of information technology enabling financial transactions via global electronic networks and of the development of the multinational banking business with emphasis on the "financing of consumption rather than on the financing of production" (p. 383). With regard to this global trend toward the financing of consumption in terms of transfers through electronic data, credit cards, and debt in modern consumer society, scholars such as Baudrillard (1988), Bocock (1993), Lunt and Livingstone (1992), and Ritzer (1995) provided insightful ideological critiques. The close textual analysis undertaken here employs the ideas discussed in their works and examines the use of ideological themes and cultural values to convey images of desired behavior, the good life, and the goals and aspirations of individuals within society. The projection as found in the banking advertising of Hong Kong reflects not only the rise of consumer culture in a Chinese society but also the values and practices necessary in a global modern consumer society.

\section{DEVELOPMENT OF HONG KONG SOCIETY, TELEVISION, AND ADVERTISING}

Although Hong Kong was under British colonial rule from 1841 to 1997, it has always been a part of China geographically. As local sociologists Lau and Kuan (1988) observed, Hong Kong "still shares many of the same cultural characteristics" (p. 33) with China even today. However, it is "generally agreed among schol- 
ars and observers that ... the boundary between traditional and modern becomes blurred" (p. 3) in Hong Kong beginning in the late 1960s. At that time, "the divergence in the paths of development between Hong Kong and China intensified" (p. 1). Since the 1970s, Hong Kong has undergone rapid social change toward "an industrializing, modernizing and predominantly urban society exposed to Western acculturation and immersed in cosmopolitanism" (p. 33).

Three strands of development in Hong Kong worked together to make the 1970 s a key decade of growth toward consumer society. This decade saw rapid changes in levels of production, in increased wages, and in the spread of television to virtually all Hong Kong households (Leung, 1996). The flourishing of advertising cannot occur without the industrialization of a society, as the cases in Great Britain and the United States illustrate (see Lears, 1994; Marchand, 1985; Richards, 1990). As Sze (1997) pointed out, the popularity of Hong Kong television began with the establishment in November 1967 of Hong Kong Television Broadcasts (TVB), the first wireless television station in Hong Kong. By 1968 , the home penetration rate reached $12.3 \%$; by $1971,60.6 \%$; by 1975 , 88.8\% (Hong Kong Television Advisory Board, 1967-1987). With this background, the television commercials throughout the 1970s are well positioned to reflect and project the changes of the society as the traditional culture interacted with the newly evolving values.

According to Yiu's (1997) classification of the important developmental stages of the Hong Kong economy, the period of industrial growth and diversification in Hong Kong lasted from 1960 through 1979 and was followed by a period of industrial transformation in the post- 1980 era. During the period from the 1970 s through the 1980s, when the banking advertisements analyzed here were produced, Hong Kong was rapidly becoming an affluent, fully developed capitalist society. Television advertising in Hong Kong thus became dominant as the society completed its growth and diversification stage and remained dominant through the industrial transformation stage.

The success of Hong Kong in moving rapidly through the stages of economic development to a stage of relative affluence also provided the population with some disposable income and further contributed to the health of the advertising industry by providing a large percentage of workers with adequate means for consumption. Leung (1996) referred to the period following the mid-1970s as one of structural change, marked by "the increasing affluence of the community, the rising educational attainment of the population, and the expansion of the financial and service sectors" (p. 11). These changes brought about the "birth of a new middle class" (p. 12), which had a different set of attitudes and social aspirations and a different lifestyle from manual laborers. With these developments in the economy, television availability, and the rise of the middle class, the 1970s and early 1980s saw the alteration and replacement of traditional Chinese values in Hong Kong and their recombination with Western attitudes toward consumption (Leung, 1996), a process 
that can clearly be seen through comparative examination of the two banking campaigns during this period.

\section{SELECTION OF THE CASE STUDIES}

This study of banking advertisements of HSB and HKB provides an excellent illustration of how traditional values change toward those more amenable to consumerism. The two selected case studies show that traditional Chinese values in financial practice that did not conform to the "organic necessities" (Sinclair, 1987, p. 24) of advertising within the capitalist system were reconfigured as Hong Kong developed into an advanced capitalist economy. It is easy to see how the traditional Chinese value of saving money directly contradicts the capitalist imperative of spending and acquisition as the signs of wealth and success. Television advertising is one of the most powerful media to provoke the desire of the audience and encourage habits of consumption and gratification that are in effect the opposite of the traditional Chinese way of thinking, which emphasized self-denial and self-sacrifice as the means of saving money and acquiring increasing wealth.

The two case studies examined here illustrate two quite distinct strategies based on two different sets of values and ideals. The first campaign, that of HSB, ran throughout the 1970 s and was accompanied by corporate sponsorship of educational programs in elementary schools to further establish a corporate identity tied heavily to the Chinese community in Hong Kong. By the 1980s, both the educational programs and highly visible thematic television advertising campaigns of HSB had virtually disappeared. On the other hand, whereas earlier HKB ads such as "Cartoon Lion" (1972) and "Vicky Wong" (1975) were simple and direct, they did not make references to social values, either traditional or consumerist. In the $1980 \mathrm{~s}, \mathrm{HKB}$ began to turn more toward new consumerist values within their advertisements, focusing on technological innovations and changes in banking services and products. The HKB ads for new services and technologies incorporated values incompatible with traditional Chinese attitudes toward saving, whereas HSB television advertising all but disappeared from view. Thus, although some of the difference between the strategies observed here can be attributed to the different corporate images and brand identities of the two banks, the focus of argument is on the historical shift of values required by the encroachment of consumerism into Hong Kong society. In fact, there are no ongoing television banking campaigns after the 1970 s that incorporate traditional Chinese values as did the HSB ads of the 1970s.

All the advertisements analyzed in this article were taken from the commercial historical archives of these two banks. HKB archivists kept a complete set of their advertisements throughout the period under examination. HSB records of advertising campaigns were less well kept, and information on production dates was in some cases estimated based on Hang Seng: The Evergrowing Bank (Chambers, 
1991). Although the set of advertisements analyzed may not be complete, it is certainly representative of the style and themes taken up by the bank at the time. Because so many ads made up each campaign and space does not allow close examination of each ad, sample advertisements representative of the whole were chosen for close analysis. In addition, brief informational ads that plainly describe products and services were not selected for close analysis.

Although the shift of values as reflected in the campaigns of both banks is at least in small part due to the different advertising strategies of the two banks, the appearance of the 1980s HKB campaigns also reflected the society that was emerging in Hong Kong at that time. Thus, this chronological juxtaposition of the HSB campaign of the 1970s and the HKB campaign starting in the 1980s is perfectly situated historically to illustrate the rapidity and thoroughness of the cultural change under discussion. The examination of these campaigns provides clear evidence that the development of modern methods in the banking industry, along with the emergence of consumer culture, required the rejection of traditional Chinese values, which were rapidly replaced by Western-derived notions of acceptable practices, honorable behavior, and the good life according to the messages underlying those campaigns. Values shifted from a focus on savings to encouraging borrowing, from self-reliance to reliance on bank loans, from hard work to easy spending, from real to symbolic status, and from harmony with nature to focus on material goods.

\section{HSB: EDUCATING THE EXCELLENT VIRTUE OF SAVING}

The name Hang Seng Bank in Cantonese means "ever-growing bank," and the history of the development of the company has followed the name. The bank was originally founded as Hang Seng Ngan Ho by S. H. Ho and three business partners in 1933. Under the leadership and influence of Ho, the philosophy of the bank upheld traditional Chinese values throughout the 1970s. The advertising strategy of HSB thus relied on references to Chinese philosophical elements such as the importance of knowledge and experience and the value of hard work. Under Ho's leadership, by the end of the 1970s, HSB was the second-largest bank in Hong Kong, with only HKB larger (Chambers, 1991). The bank was important to the development of Chinese businesses and worked primarily with Chinese people as Hong Kong grew into an industrialized society. Compared to other non-Chinese banks such as HKB, HSB represented a reputable and stable banking outlet where Chinese customers felt comfortable because both bank and customers shared common traditional Chinese values. Throughout the early decades of the life of the bank, the philosophy of giving something back to the society was reflected through the charity actions and advertisements of HSB that emphasized hard work and close-knit community as the means to achieve a better life. 


\section{The Virtue of Saving}

Throughout the television ads of HSB, references to Chinese values, philosophical issues, practices of life, and Confucianism were included as the primary elements of persuasive appeal. For example, one ad used the occasion of Chinese New Year (CNY) to present its central character and spokesperson as the God of Fortune (see Figure 1). The God of Fortune greeted viewers with a five-character poem wishing people a happy and prosperous new year. The poem represented a traditional type of Chinese life practice and translates as "practice saving in the teenage years, work energetically when you are still young, then in your middle life you will get everything for your life, and in old age you will have a happy family life." The key message of the ad apart from the simple and literal greeting for CNY reflected some of the principles of HSB at that time. The merit and practices directed to viewers were those found in Chinese traditional thinking and values. As Feng (1988) summarized, "Chinese traditional values include not only Confucian social ethical values, but also Taoistic natural ethical values" (p. 58). Social ethical values can include "love of one's fellow men [and] honesty" (p. 58), and natural ethical values can refer to "self-regulation, self-enrichment, [and] self-prudence" (p. 58). Clearly, the ad preached to the audience on the righteousness of Chinese traditional values of "self with other, with society, and with nature" (p. 58). These values were linked abstractly with the security of savings, such that money represented peace and sta-
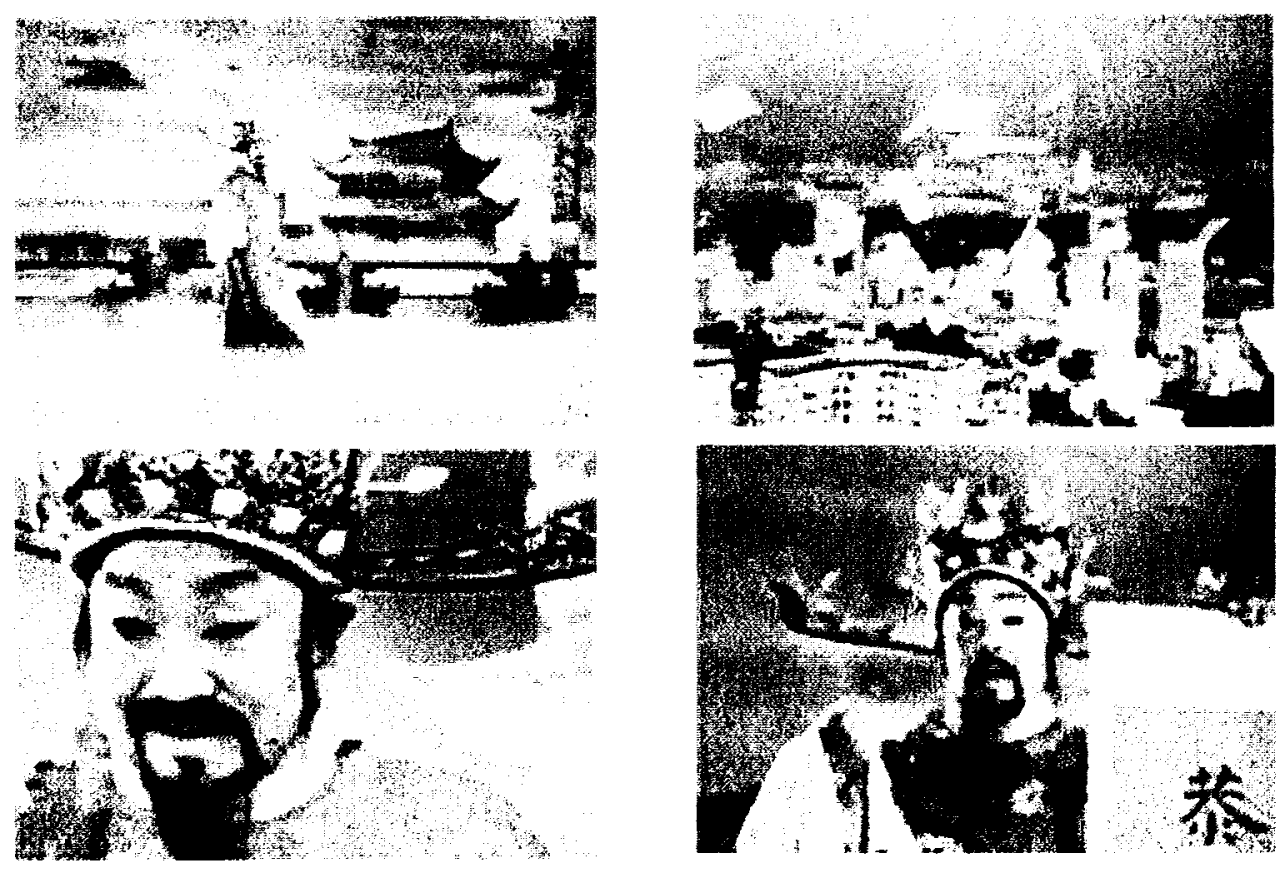

FIGURE 1 God of Fortune, Hang Seng Bank, 1973. 

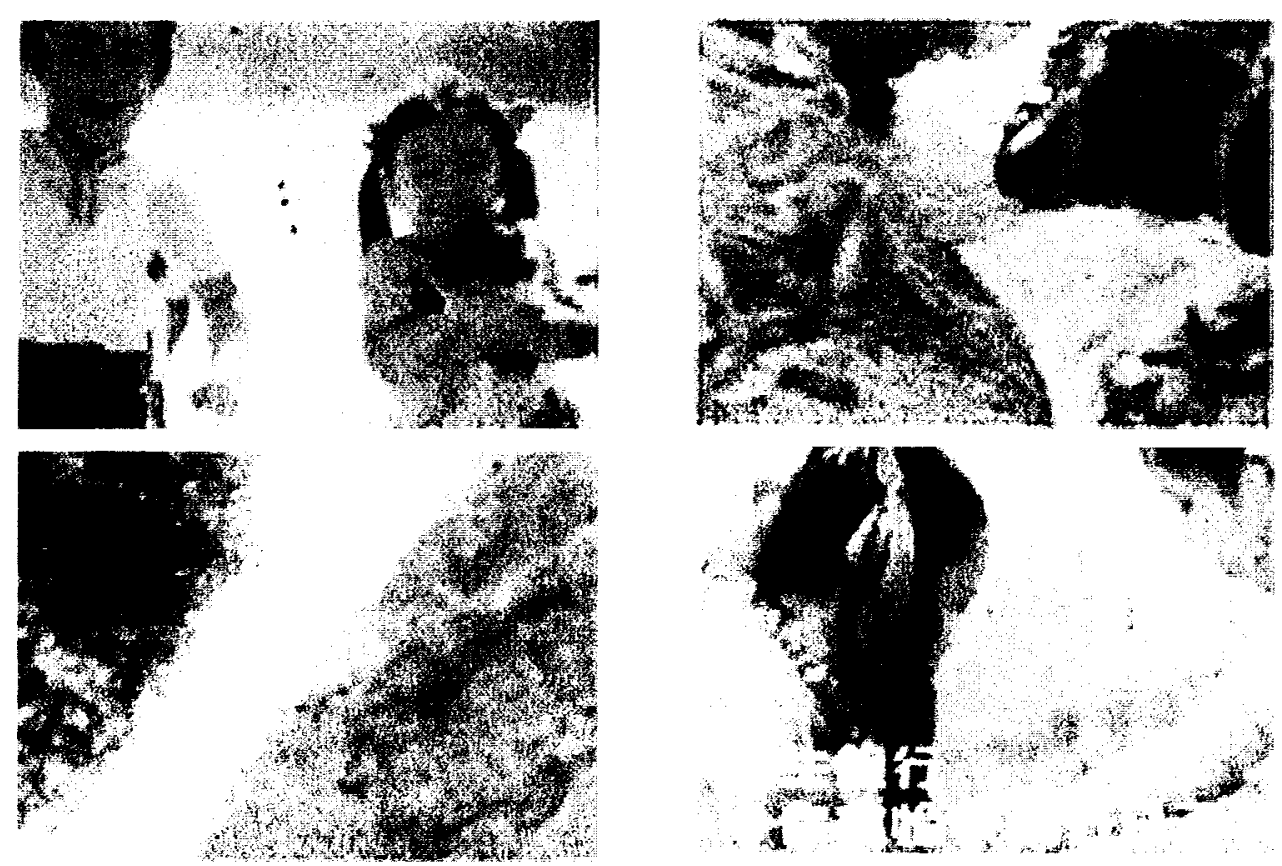

FIGURE 2 Little Water Drop, Hang Seng Bank, 1972.

bility rather than the elements of choice, leisure, and purchasing power that were emphasized in the later HKB campaign.

Two additional HSB ads from the 1970s illustrate the emphasis the bank placed on savings as a personal practice connected with the broader traditional Chinese values just described. One of their very early ads, Little Water Drop (see Figure 2), produced around 1972, illustrated the virtue of saving by using metaphor accompanied by a musical jingle. The jingle included the line "even a little water drop can gather into an ocean. Even a grain of sand can build the land." The visual provided a match for the jingle, opening with three young children chasing their puppy on the beach and flying a kite. The visual cut to an image of a drop of water while the jingle was about the little water drop. The water drop was superimposed onto a visual of a big waterfall, and the waterfall cut to the ocean, providing the literal visual representation of the jingle lyrics. Next, some floating sand was shown, and it formed a pile that became a piece of land. The images of the ocean and the land were intercut with each other, and then the visual returned to the children playing in the sand. Finally, the male voice-over stated that "accumulation from very small can become very great. Hang Seng Bank can arrange a happy life for you."

Sand in the ad is not only a metaphor for savings but also a familiar plaything that may invoke fond memories or hopes of future fun times. As Lunt and Livingstone (1992) noted, "attitudes to finances reflect more general underlying values which guide people's attitudes and behaviours in many life domains" (p. 119). As can be seen in this ad, the emphasis was on dependable growth from a small amount to an 
exaggerated large amount (a whole ocean), suggesting that full success and happiness can be found through the simple practice of saving. This traditional attitude toward money and the personal financial practices that will bring success, as well as the type of success that is depicted, are in clear contrast to later banking ads in Hong Kong. Not only did the HSB ad focus on traditional values and practices connected with money, it also depicted success as simple enjoyment of life unrelated to consumption of goods. The kite, an item that can be purchased for a very small price or even made by hand, was the only consumer item that appeared in the ad. The children played together in a natural setting, enjoying each other and natural elements, and they used their imagination and energy to create fun.

\section{The Value of Hard Work}

An ad produced for the 40th anniversary of the HSB (see Figure 3 ) in 1973 drew on the same themes used in the earlier ads but placed even more emphasis on the idea of working with Hong Kong people to ensure a better future through mutual efforts. This ad included many images of building construction in the city, on the harbor, and so forth, generally giving the impression of the hustle and bustle of the society as it progressed into its more modernized form. The streets were filled with vehicles, airplanes flew overhead, and ships sailed through the harbor. These images were contrasted with images of a farmer plowing land with a single ox. The contrast

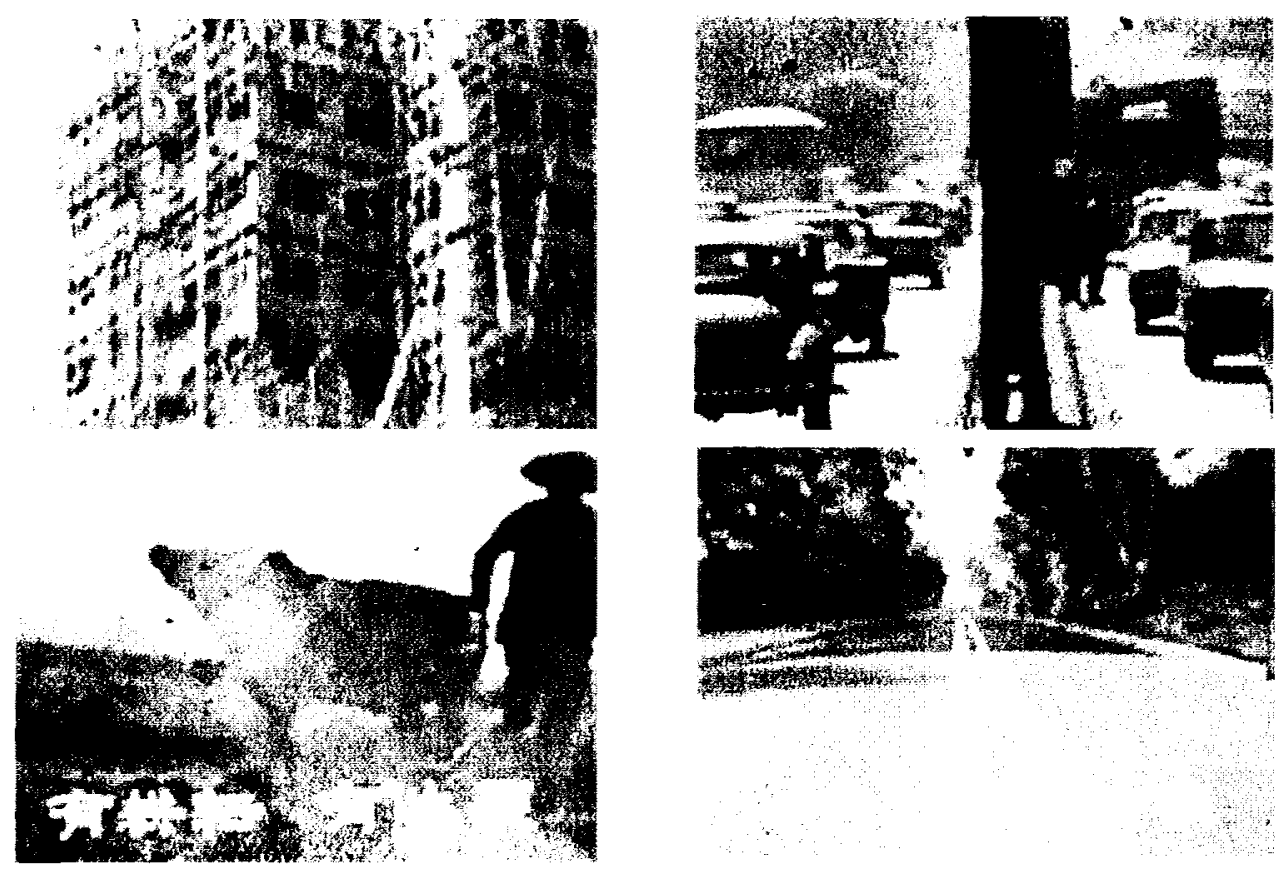

FIGURE 3 Hang Seng Bank 40th Anniversary, 1973. 
implied that society had developed quite far from the old farming method to the more modern symbols of high-rise buildings and airplanes. However, it also seemed to suggest that the farmer provides both nourishment and a solid past on which the development is based. The visuals are somewhat open to interpretation as to the position and meaning of the farmer in relation to the modern city, but the verbal text provided the anchor for these floating signifiers. It said, "energetic Hong Kong, progressive Hong Kong, it all depends on cultivation and hard work."

The second part of the ad again depicted the farmer working with the ox, plowing a row for planting. This visual was intercut with an image of a paved road. The camera kept moving forward, making the road pass quickly under the viewer's eyes. Meanwhile, the background music was fast paced and enhanced the feeling of forward movement. Subtitles read "with cultivation, with harvest, with hard work, with future." The ad closed with the moving road image again, along with the HSB logo. Thus, progress and future were re-emphasized as the central themes of the ad but were connected with traditional values. As a whole, the ad conveyed the idea that if people work hard, they can have a good future, just as Hong Kong as a society did in moving from simple farming techniques to an industrialized and modern city in just a short time. The bank subtly associated itself with the progress that Hong Kong made toward a happy, prosperous future but again did not mention material goods that can be obtained with money, or any of its services, advantages over competitors, and so forth.

Whereas the 40th anniversary ad just described conveyed a general message about hard work applicable to the whole society of Hong Kong, a later example took a much more personal approach. This ad focused on a blue-collar worker (see Figure 4) telling his story in images without voice-over narration. The story started with a man working on a pier unloading stock from boats. He passed a truck in which the driver was taking a rest in the cab and seemed to envy the truck driver. The following scene showed a group of pier workers gathered together and gambling for fun. The visual zoomed away to the central protagonist, who was eating lunch alone. He took out his HSB passbook and smiled in satisfaction. Then, the visual cut to the next scene, which showed a new truck with the young man inside. His friend congratulated him on having his own truck. Next, he was shown delivering goods and then instructing workers. Instead of wearing the simple t-shirt he had been wearing, he was wearing a work shirt with buttons and pockets. He inspected a row of trucks, and his former colleague cleaned them and called him "boss." The visual ended with a shot of him inspecting the trucks, and a male voice-over provided the only anchoring words in the ad: "It is not just luck to be a success. It is about hard work and ability." This ad illustrated and praised the value of hard work and promoted the traditional belief that if you work hard you can achieve success in life. Success is defined purely as position rather than as the purchase of goods or enjoyment of leisure time. The content of this ad and the others reflects a production-based rather than a consumption-based society and reflects the traditional val- 

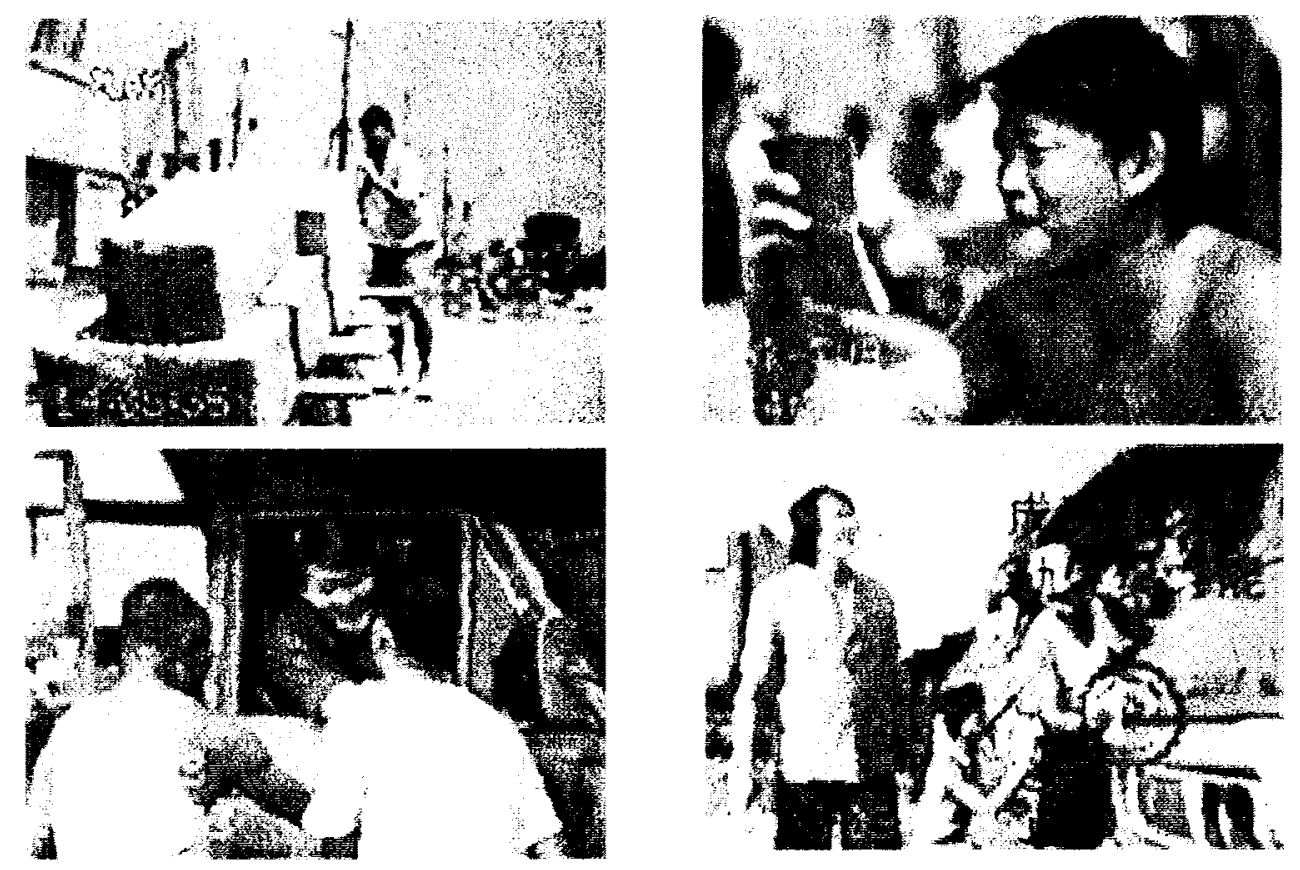

FIGURE 4 Truck Driver, Hang Seng Bank, 1979.

ues of self-reliance, hard work, harmonious family and society, and gradual accumulation toward security and position.

As Ritzer (1995) pointed out, banks traditionally tried to get people to be debt-free and to engage in the practice of saving. The HSB ads in this direction could easily follow both the banking tradition and the tradition of Chinese values because they were together in their concept that hard work and saving were the correct path to wealth and happiness. This theme of saving and hard work in the HSB ads continued through the mid-1970s. The ads used very similar techniques by linking the idea of saving and hard work with the idea of happiness and personal satisfaction, without any reference to consumer goods or the ideas and practices of consumption. They also subtly conveyed the idea of harmony between people and nature. Happiness was depicted as simple enjoyment of family members or friends in a peaceful or familiar setting. There was no reference at all to what the accumulated money could buy in the material sense. The only "good" depicted was the enjoyment of a simple life in harmony with nature. The attitude toward the importance of hard work and the link between saving and future happiness were easily connected through the traditional values referenced in the ads.

\section{HKB: PROMOTING THE PLEASURE OF BORROWING}

The Hongkong and Shanghai Banking Corporation's HongkongBank (HKB) was founded in 1865 by a group of British and foreign businessmen in Hong Kong 
shortly after the end of the Second Sino-British War (King, 1991). The name in Chinese, Wayfoong, means in the literal sense "a focus on wealth." It was the sole British overseas bank that had its headquarters in Hong Kong, and by 1900 it had become the dominant local bank as well as very powerful in China. As a sort of central bank, which produces most of the local currency, it serves as the main bank of the Hong Kong government. Unlike HSB, HKB does not have any special commitment toward the Hong Kong Chinese community but rather distinguishes itself as a British-owned bank (King, 1991). The HKB campaigns project a more Westernized image and focus more on the commercial purposes, services, and values related to consumption. Their early 1980 s campaigns picked up the technological development, diversification of banking services, and economic transformation of Hong Kong society, providing a clear contrast with the HSB campaigns described previously. This campaign was moving toward an emphasis on symbolic status achieved through material goods rather than actual achievement and position gained through hard work, as in HSB campaigns.

\section{Spending with Convenient Cash}

In the electronic teller counter (ETC) campaign, the elements of ease and convenience were emphasized regularly. ETC provided a computerized machine teller that could be utilized at any time of day or night to withdraw or deposit money. This campaign introduced the newly available service in 1980. Because ETC was a new service, the ads focused on what it was, how to apply for it, and what it provided to the user. Sword Man (see Figure 5) depicted a character taken from a popular television epic at the time, performed by Cheng Siu-tsau. The ad first stated the problem that sometimes a person needs money at an awkward time when the bank is closed. The setting was at night outside one of the bank branches where the television character was attacked by several people. He pulled out the ETC card, put it into the bank machine slot, and punched his code number with one hand while defending himself from the attackers with the other. When the money appeared, he addressed the audience, saying, "so easy you can do it with one hand." From this very first ETC ad, the emphasis was on withdrawal rather than deposit of funds. The service itself leads to a more casual attitude toward spending, as it eliminates the need to plan how much money to keep on hand for likely expenditures, and the ad pushed the consumer even further in this direction, indicating that the card is "just like money in your pocket" and removing the connection between work and money as well as the connection between what you put into the account and what you can take out. The emphasis on ease and convenience carries with it a lack of concern for how much money is spent and with what frequency.

Another ad from the same campaign, Amah (Chinese domestic helper), more literally made the connection between the convenience of the machine and spending. This ad (see Figure 6) depicted an Amah with the male voice-over saying that some- 

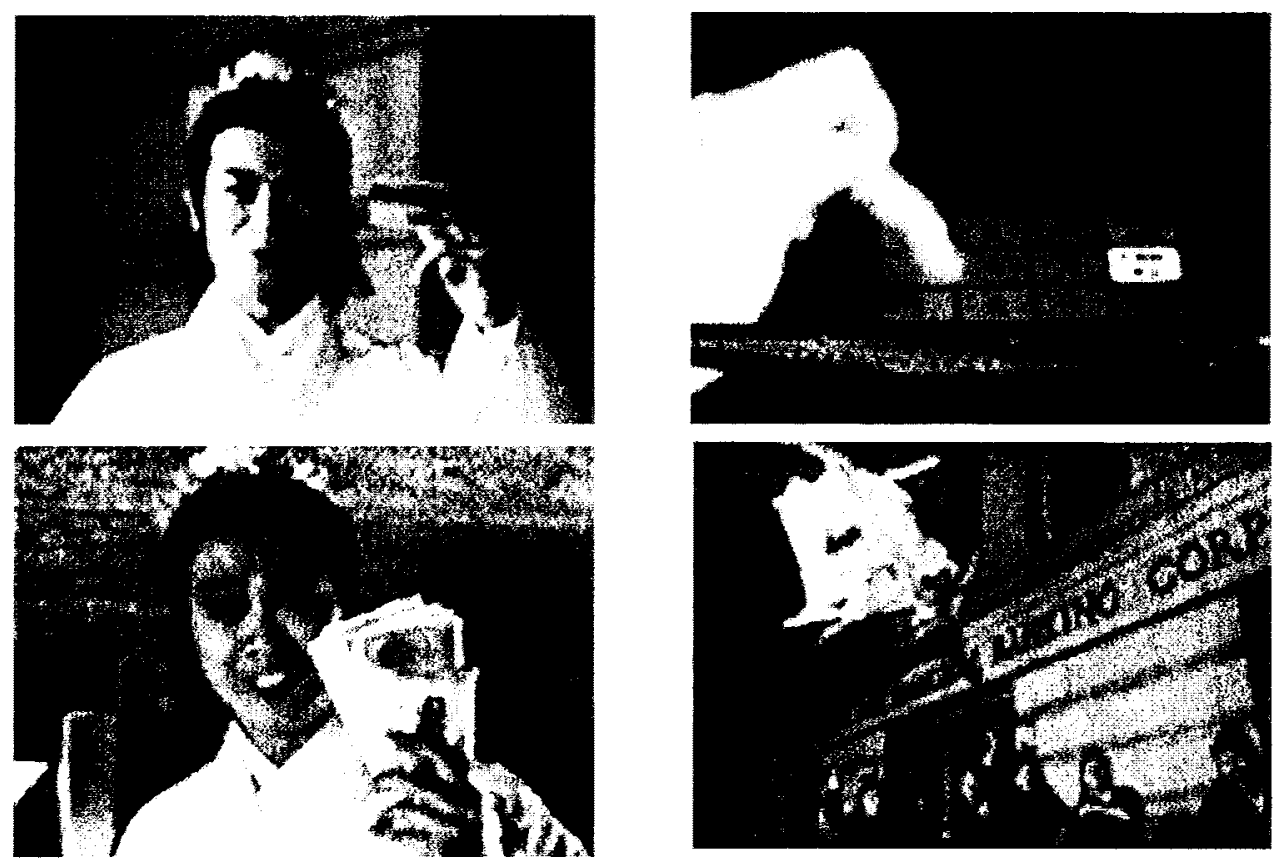

FIGURE 5 Sword Man, HongkongBank, 1980.
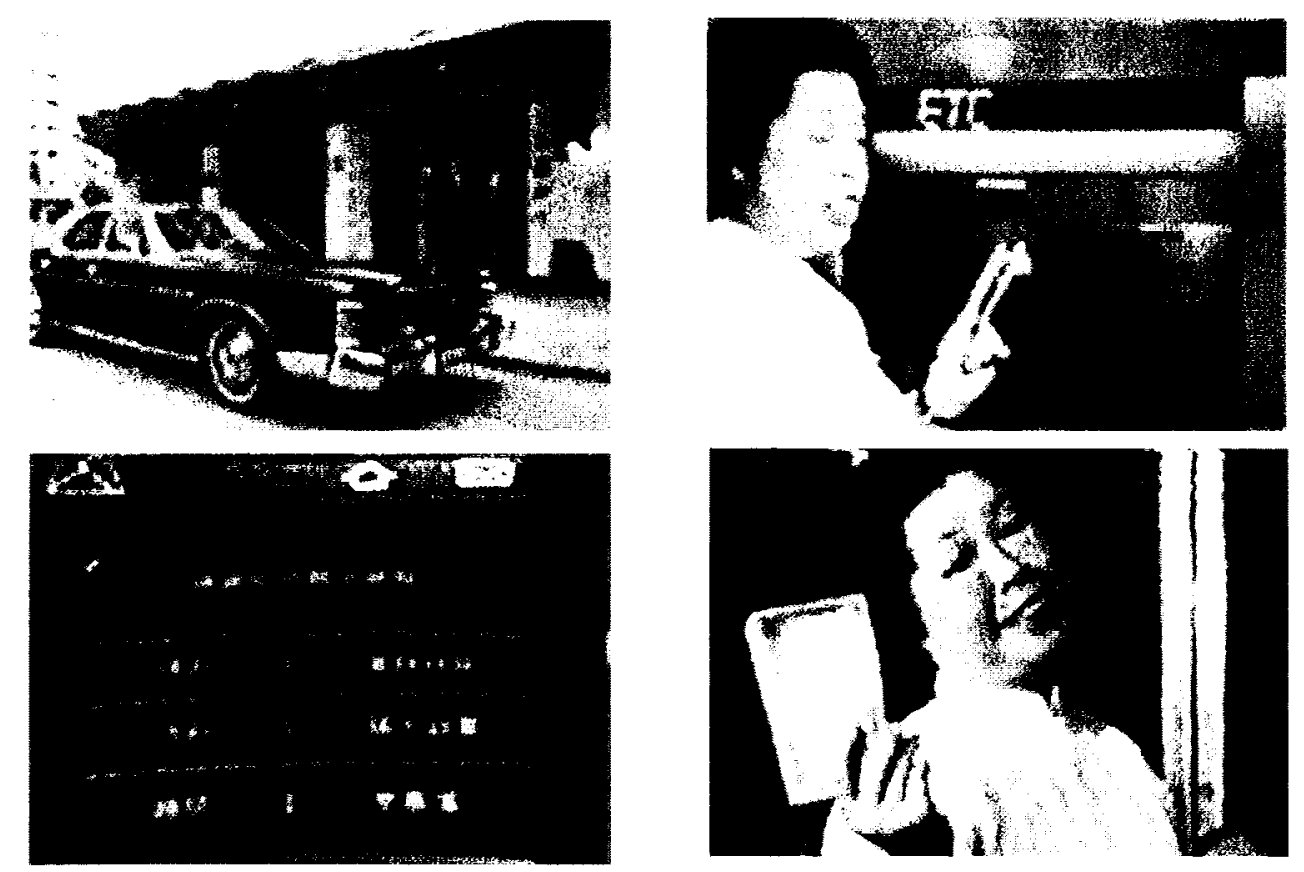

FIGURE 6 Amah, HongkongBank, 1980. 
times you need cash for a holiday. The Amah got out of her boss's Rolls Royce and directly addressed the audience, saying how easy it is to use ETC. She demonstrated using the card to get cash, saying "now you can have cash seven days a week. Otherwise, how could I get enough to spend?" Thus the ad emphasized that the function of the machine is to make withdrawal more convenient and potentially more frequent. The deposit function was not mentioned in this or any of the other ads in the introductory campaign. Rather, convenience was mentioned over and over, and ETC was linked with the ideas of instant cash and spending money.

Unlike the HSB commercials discussed previously, these campaigns made no mention of hard work and certainly were not promoting saving as a valuable practice. The virtues of saving and hard work have disappeared in these HKB ads, replaced by a new set of values emerging in the procredit era. These new values of consumption and easy spending were further developed and emphasized in the HKB campaigns for VISA ${ }^{\circledR}$ Card and personal installment loans (PIL).

\section{Encouragement of Casual Consumption Through the Credit Card}

As Ritzer (1995) pointed out, the credit card is now an American icon that "is treasured, even worshipped, in the United States and, increasingly throughout the rest of the world" (p. 1). Because much of the consumption and lifestyle development in the society of Hong Kong has followed the experience of the West (Leung, 1996), the credit card phenomenon eventually evolved in Hong Kong, and the early 1980s proved to be the most important phase in the development into the credit era. Following Simmel's (1907/1990) notion of the philosophy of money, Ritzer (1995) defined the function of credit cards as "permit[ting] people to spend more than they have" (p. 3). Indeed, even in the television advertisements from the first launch of the credit card in Hong Kong, such a depiction of casual consumption images can be commonly found. Naturally, this new development represented a clear move away from the traditional values depicted in the earlier HSB campaigns because "the credit card is yet another invention of the banks and other financial institutions to get people to save less and spend more" (Ritzer, 1995, p. 10).

The HKB VISA ${ }^{\circledR}$ Card campaign introduced credit cards available from the bank. Its first ad, launched in 1980 (see Figure 7), opened with the visual display of the VISA ${ }^{\circledR}$ Card with a narrator saying that "this is a VISA ${ }^{\circledR}$ Card, but not just any VISA ${ }^{\circledR}$ Card. It is VISA ${ }^{\circledR}$ from HongkongBank. The international VISA ${ }^{\circledR}$ Card that lets you make the important purchase when you need to." The visual display of the VISA ${ }^{\circledR}$ Card presented the card as a sign of consumption. The credit card became a sign of purchasing power and convenience that allows for consumption without cash notes and even without savings in the bank. The consumption activities depicted in the ad included using the card to pay for dinner in a fancy restaurant 

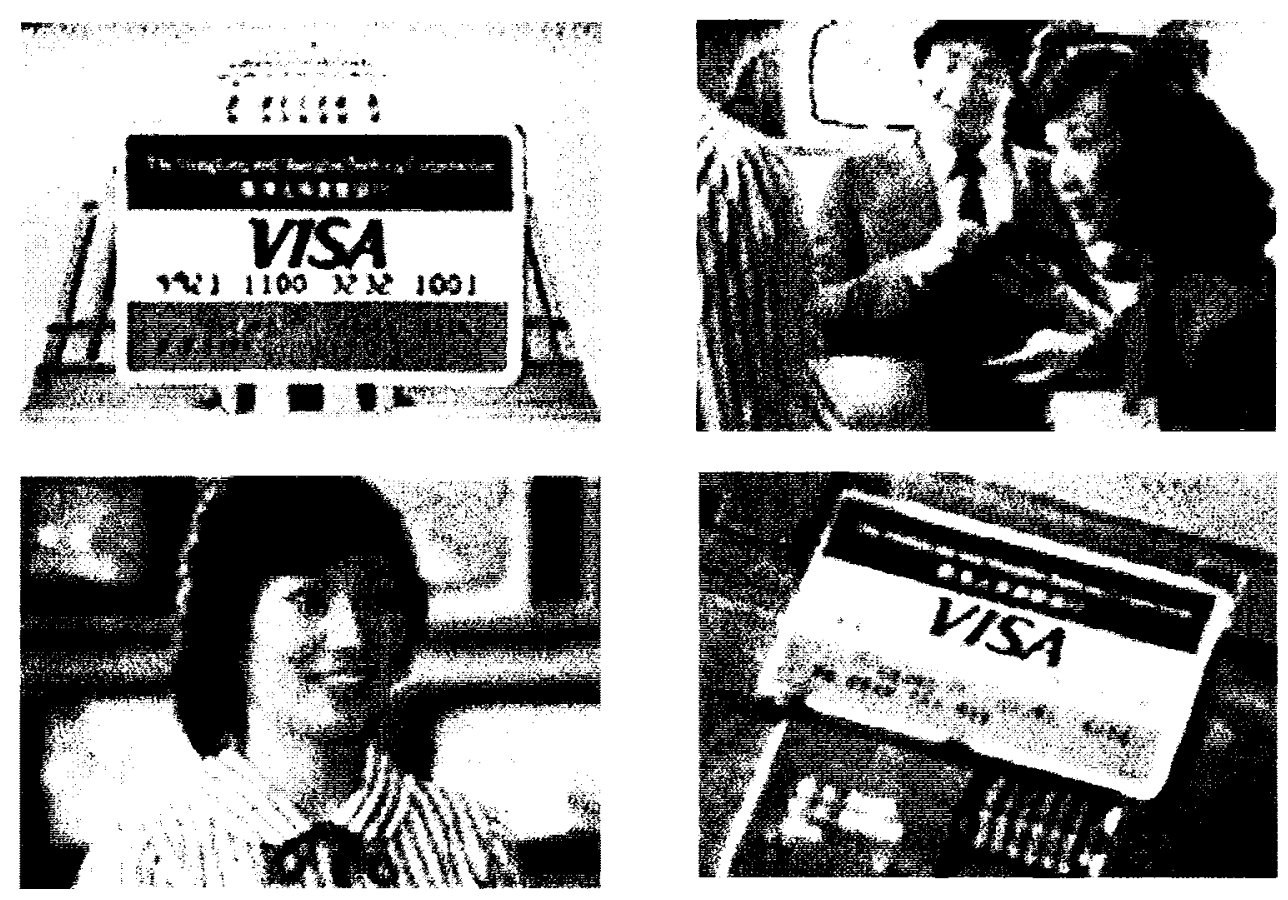

FIGURE 7 Launch of Visa ${ }^{\circledR}$ Card, HongkongBank, 1980.

and using it to purchase household electronic appliances, clear signs of affluence for the emerging middle class in Hong Kong.

The follow-up ad in the same year, Suit (see Figure 8), depicted more purchasing scenarios. The narrative mentioned that this card can make any purchase so much easier and simpler, including "things you have to buy" and "things you want to buy" and even "the things you really do not intend to buy." In this ad the things you have to buy were represented by household electronic appliances, the things you want to buy were represented by a fancy hat for a woman, and the things you do not intend to buy were represented by a toy. In the restaurant scene, the man hardly looked at the bill but immediately put out his credit card to pay. The card was accepted happily by the waiter, whose attitude further confirmed the status of the user. This ad presented the credit card not only as a sign of status but also as a trouble-free means of acquisition in a variety of circumstances.

In Baudrillard's (1988) terms, this "most modern form of payment, [that seemingly can] free us from checks, cash, and even from financial difficulties at the end of the month" (p. 34) easily lends itself to such a trouble-free representation. As Ritzer (1995) pointed out, credit cards can "smooth out consumption by allowing us to make purchases even when our incomes are low" (p. 4). These introductory ads depicted the advantages and convenience of the card, which allows the purchase of such unnecessary items as a fancy restaurant meal and a pretty hat. As Baudrillard stated, "in order to become an object of consumption, the object must 

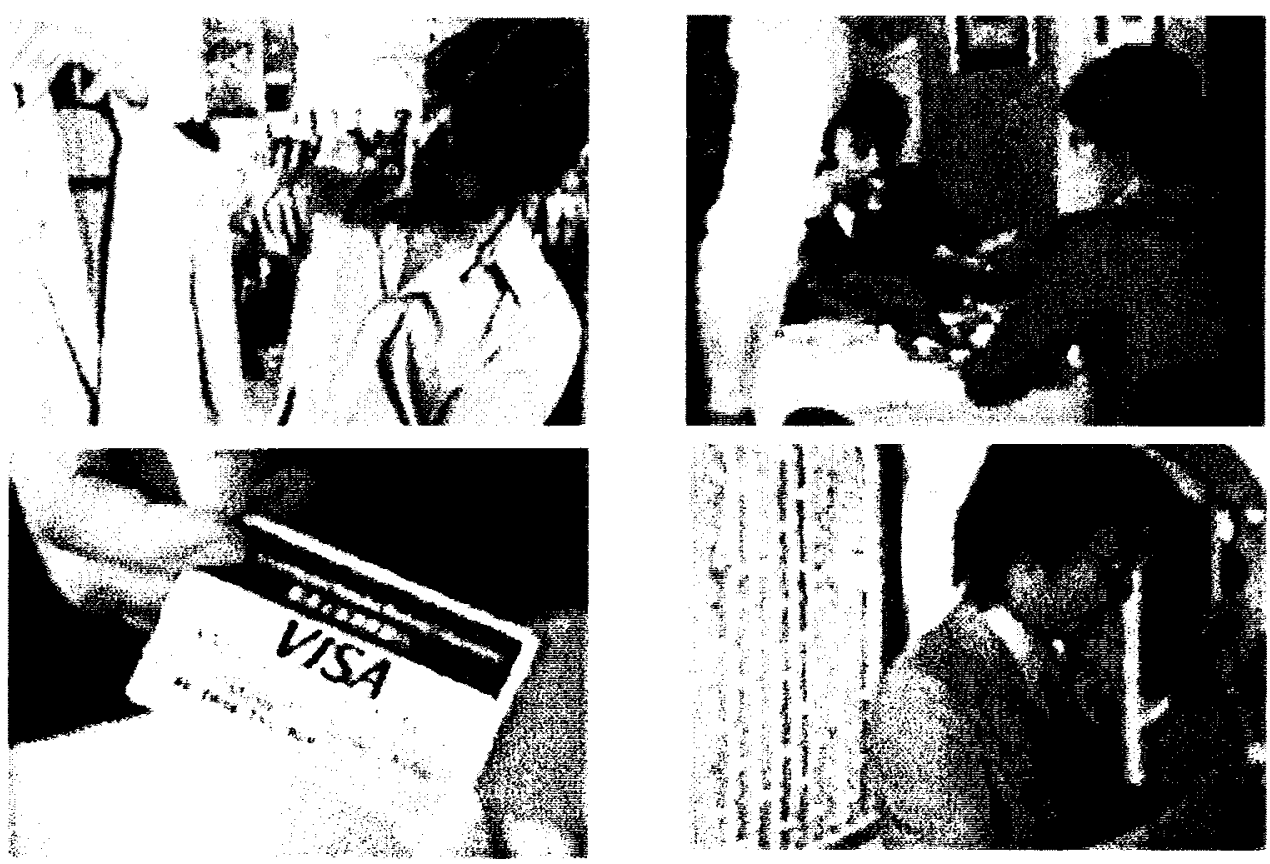

FIGURE 8 Suit, HongkongBank, 1980.

become a sign" (p. 22). The objects became signs of power, happiness, and status. The status of position represented in the HSB ads was progressively replaced by the symbolic status of credit and purchasing power. The VISA ${ }^{\circledR}$ ads took the first step in this process.

Ritzer (1995) warned about the hidden dangers of credit cards, observing that although "credit cards seem to be the means to wealth, happiness, and liberation from our otherwise humdrum lives" (p. 11), they actually end up serving as "instruments of bondage locking people into a lifetime of indebtedness" (p. 11). As can be seen from the VISA ${ }^{\circledR}$ Card ads from HKB, although a line such as "the things you really do not intend to buy" may be intended as humorous, it is also an illustration of how the card can manipulate demand. Also, by displaying different cases and problems (e.g., from having to buy electronic appliances to wanting to buy a hat) followed by the solution of the card, the ads illustrate what Baudrillard (1988) criticized in noting that "everything is appropriated and simplified into the translucence of abstract 'happiness,' simply defined by the resolution of tensions" (p. 34). The images of these ads provided an easy solution to the viewers and projected a kind of satisfactory and happy picture that they could obtain by owning the card. The main reason is that "the money involved in credit card transactions seems abstract and unreal" (Ritzer, 1995, p. 60). Clearly the HKB ads enhanced this effect by eliminating references to work, accumulation, and gradual growth toward security and status, elements fundamental to the traditional Chinese value system that were still present in the HSB ads of the late 1970s. 
Although the ads did not overtly state that debt is good, they promoted associations between credit cards and material consumption that more subtly encourage debt-producing behaviors. The move into the realm of buying things that are unnecessary and not desirable and purchasing things that are not at all considered ahead of time placed additional focus on consumption in connection with satisfaction and enjoyment of life. Thus, the HKB VISA ${ }^{\circledR}$ Card campaign took another step toward the values of consumption and lifestyle and away from traditional values of self-reliance, hard work, and saving. Although the element of debt lies unspoken behind the mechanism of a credit card, it is not an explicit requirement of a life of consumption. This step was not taken until the PIL was introduced in 1983.

\section{The Enjoyments of Loans}

In Hong Kong, as elsewhere, modernization has meant a significant shift in the purposes, goals, and techniques of banking and bank advertising, such that today "while banks are discouraging savings, they are in various ways encouraging debt" (Ritzer, 1995, p. 10). Whereas the VISA $®$ Card uses the idea of credit to encourage consumption, the PIL makes debt a way of further enhancing the possibilities of gratification through material goods. This debt concept is contradictory to traditional Chinese thinking, bringing the values espoused in the HKB ads in clear opposition to those values emphasized in the earlier HSB campaigns. Debt is not only clearly contrary to traditional Chinese values but also a concept imported from the West. As Lunt and Livingstone (1992) observed, in the West people believe that "debt is a normal part of everyday life and nothing to be ashamed of" (p. 119). Therefore, in depicting the use of the PIL for a wide variety of everyday and extravagant expenses, the ads served as a legitimization of the practice already made acceptable in the West, showing debt as something acceptable, right, normal, or even preferred rather than presenting the traditional Chinese view of debt as shameful.

The PIL ads focused not on the specifics of how to take out a loan but rather on how the bank was acting like a friend by helping the customer. The ad (see Figure 9) that launched this campaign, entitled, Thank You HongkongBank (1983), opened with the scene of the harbor view from the peak. A couple was depicted watching the sunset over the harbor and discussing something, with the conclusion, "let's ask HongkongBank," just as a person may say, "let's ask our friend." The second scene showed another couple in an electronics store. They were short of money to purchase the household appliances they wanted and said they would talk to HongkongBank. Finally, a third scene showed another young couple standing in front of the window display of a travel agency. The visual cut to the inside of a bank with a poster advertising the PIL. Again the visual cut to show the results of the problems of the three couples depicted earlier. The couple who was watching the sunset was at their wedding banquet, the electronics store couple was sitting in their 

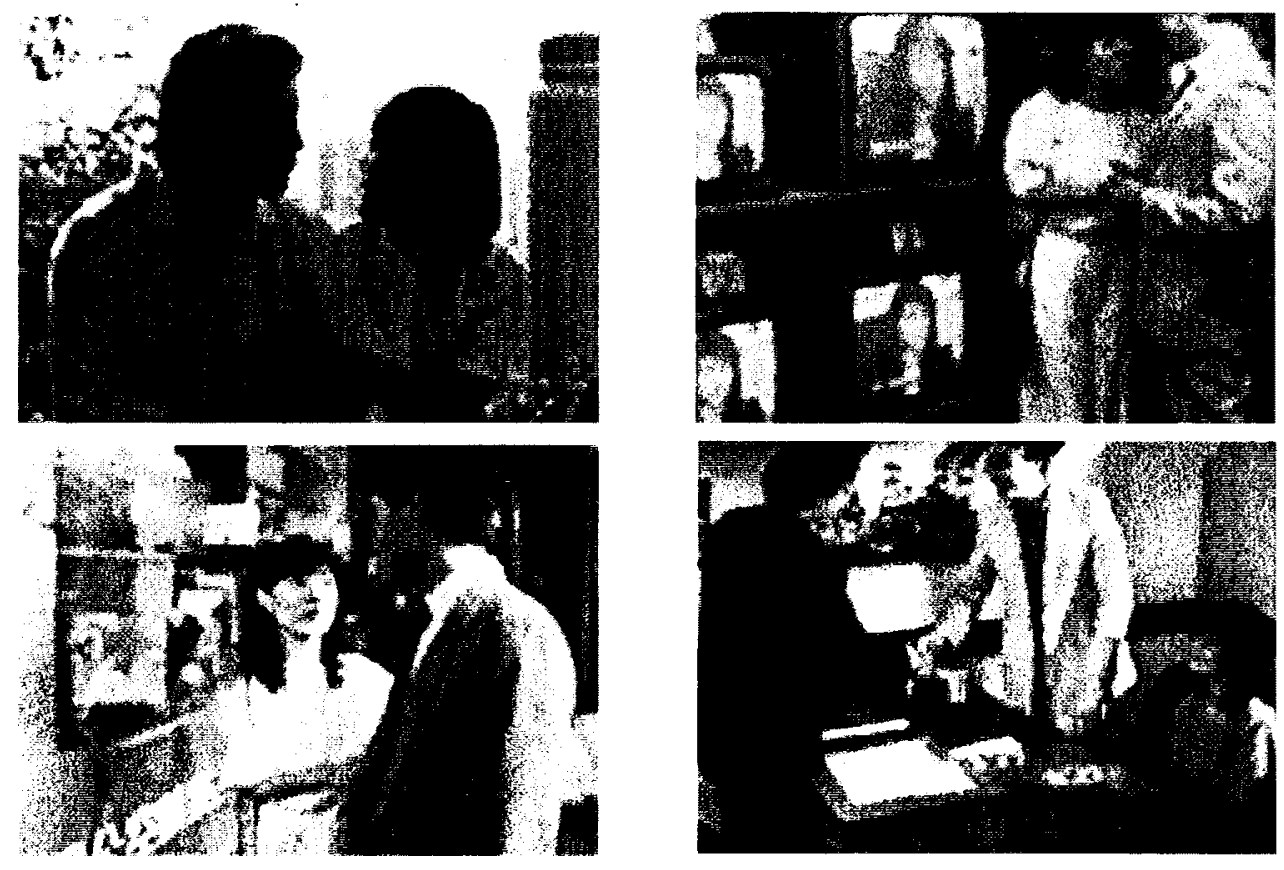

FIGURE 9 Thank You HongkongBank, 1983.

living room watching a new television, and the travel agency couple was in front of a check-in counter at the airport. All of them said, "Thank you HongkongBank."

Advertisements help in "constructing consumers' sense of themselves as composed by particular kinds of product-images" (Goldman, 1992, p. 34), and these PIL ads helped consumers imagine themselves in new situations brought about by the consumption of goods made possible through a loan. Thus, the ads sold not only the idea of a loan but also images of lifestyles and identities made possible by consumption. The young couples desired consumer goods as the route to happiness, yet they did not seem to work for these goods. Instead, their desires were immediately gratified through the acquisition of debt. Again the elements of actual money, true costs, work, and savings were eliminated from view. A happy life was depicted as one that includes quick purchase of goods to fulfill material desires rather than one that builds slowly toward a stable and secure lifestyle.

With the simple technique of showing a series of desires linked up with the ability of the bank to help obtain these desires immediately, before the hard work has been done to earn them, these ads implied that debt is a good way to solve problems. The shift here is more significant than simply encouraging the sale of a particular service and more important than simply selling the idea of a new image of life and lifestyle. In fact, the shift from the earlier emphasis on savings to the final stage of the PIL ads involved a fundamental replacement of values. This shift was necessary to the successful functioning of industrial capitalism and was thus inevitable as the economy of Hong Kong developed. The comparison of these two bank case studies, 
with the later one used to sell a range of new technologically innovative services, shows a dramatic shift in values and desires projected within a very small time frame. Whereas the earlier HSB ads were free of consumer goods, the HKB campaigns showed a wide range of goods, lifestyle images, and materially solvable problems to help instill desires and encourage consumption. With the easy money provided by loans, consumers' dreams can come true, and the practical value of the products in terms of money and labor is no longer an issue to be considered.

Thus, through the projection of visual depiction of the ad at the symbolic level, the PIL ads from HKB at this time reflected the society of Hong Kong as evolving toward the modern capitalism stage. According to Bocock (1993), many societies have a large proportion of those

Who increasingly are hooked into the culture of consumerism. This means that many people continue to desire to be purchasers, consumers, even when they cannot afford to buy all the things and pleasurable experiences which they might wish as a consequence of seeing what is on offer in advertisements, and in television programmes more generally. (p. 76)

By depicting debt as a normal activity that is acceptable in nearly any situation where a large expenditure is needed or desired, the HKB ads definitely contributed to this phenomenon that is characteristic of "Western capitalist social formations" (Bocock, 1993, p. 76). Of course, the ads did not mention interest rates or fees, the terms or methods of repayment, or the amount of money to be borrowed. They simply took consumption for granted and invited consumption with money not yet earned. The introduction of the VISA ${ }^{\circledR}$ Card and the PIL represents the development of Hong Kong toward a consumption-based society. To be modern is not just to be surrounded by goods but also to utilize modern practices and habits of consumption as originally developed in the West, such that "the consumer goods and experiences do deliver, for some, the goal of life-consuming things" (Bocock, 1993, p. 51), in Hong Kong as in the West. Not only are people no longer encouraged to save, but they are encouraged to go into debt to pay for the symbols of modern life. Therefore, debt in its various forms, including credit cards and bank loans, becomes one of the necessities of modern life. To encourage debt, the ads must alter traditional values, placing self-reliance and work in the background and presenting goods and spending as the way to achieve happiness.

\section{CONCLUSIONS}

This article has provided a comparative case study to illustrate how "consumerism has become the practical ideology of capitalism, one which legitimates capitalism in the daily lives and everyday practices of millions of inhabitants of western, and 
other, social formations" (Bocock, 1993, p. 116). In doing so, consumerism reconfigures the traditional values of a society with values required by capitalism and consumption. Examples from the Hong Kong cases illustrate this phenomenon. This analysis has shown not only that the development of capitalism requires the abandonment or alteration of traditional values but also that the process of modernization in Hong Kong was a process of Westernization, through which values and ideals developed in the West were imported to carry out the imperatives of consumer capitalism. In Hong Kong, modern consumer culture truly arose from the ashes of traditional culture, bringing with it a change not only in habits of consumption but also in fundamental cultural values and ideals. In examining these relations, this article has explicated the ideological functions and meanings of advertising that contributed to the fertilization and sustenance of the life of the capitalist system in Hong Kong.

\section{ACKNOWLEDGMENTS}

I thank Hank Seng Bank and HongkongBank for providing tapes of their archived advertisements. I am grateful for the detailed and considerate attention given to the article by editors Sharon Mazzarella and Matthew McAllister. Thanks also to my dissertation supervisor, Dr. Jackie Kwok at the Hong Kong Polytechnic University.

\section{REFERENCES}

Barnet, R. J., \& Cavanagh, J. (1994). Global dreams: Imperial corporations and the new world order. New York: Simon \& Schuster.

Baudrillard, J. (1988). Jean Baudrillard: Selected writings (M. Poster, Trans.). Oxford, England: Polity. Bocock, R. (1993). Consumption. New York: Routledge.

Chambers, G. (1991). Hang Seng: The evergrowing bank. Hong Kong: Heng Seng Bank.

Ewen, S. (1976). Captains of consciousness: Advertising and the social roots of the consumer culture. New York: McGraw-Hill.

Feng, L. (1988). Chinese modernisation and social values. In D. Sinha \& H. S. R. Kao (Eds.), Social values and development: Asian perspectives (pp. 56-64). Newbury Park, CA: Sage.

Goldman, R. (1992). Reading ads socially. New York: Routledge.

Hong Kong Television Advisory Board. (1967-1987). Report of the Television Advisory Board on the progress of television in Hong Kong (Vols. 1-12). Hong Kong: Government Printer.

King, F. H. H. (1991). The history of the Hongkong and Shanghai Banking Corporation (Vol. 4). Hong Kong: Hongkong and Shanghai Banking Corporation.

Lau, S. K., \& Kuan, H. C. (1988). The ethos of the Hong Kong Chinese. Hong Kong: Chinese University Press.

Lears, J. (1994). Fables of abundance: A cultural history of advertising in America. New York: Basic.

Leiss, W., Kline, S., \& Jhally, S. (1990). Social communication in advertising: Persons, products and images of well-being (2nd ed.). New York: Routledge.

Leung, B. K. P. (1996). Perspectives on Hong Kong society. Hong Kong: Oxford University Press. 
Lunt, P. K., \& Livingstone, S. M. (1992). Mass consumption and personal identity: Everyday economic experience. Philadelphia: Open University Press.

Marchand, R. (1985). Advertising the American dream: Making way for modernity, 1920-1940. Berkeley: University of California Press.

Richards, T. (1990). The commodity culture of Victorian England: Advertising and spectacle, 1815-1914. New York: Verso.

Ritzer, G. (1995). Expressing America: A critique of the global credit card society. Thousand Oaks, CA: Pine Forge.

Sandage, C. H. (1989). Some institutional aspects of advertising. In R. Hovland \& G. B. Wilcox (Eds.), Advertising in society: Classic and contemporary readings on advertising s role in society (pp. 3-10). Lincolnwood, IL: NTC Business Books. (Original work published 1972)

Simmel, G. (1990). The philosophy of money (2nd ed.). New York: Routledge. (Original work published 1907)

Sinclair, J. (1987). Images incorporated: Advertising as industry andideology. New York: Routledge.

Slater, D. (1997). Consumer culture and modernity. Cambridge, England: Polity.

Sze, M. H. (1997). Mass culture and consumption life [In Chinese]. In K. M. Wang (Ed.), Hong Kong history: New perspectives (Vol. 2, pp. 593-615). Hong Kong: Joint Publishing.

Yiu, M. K. (1997). The history of industrial development in Hong Kong [In Chinese]. In K. M. Wang (Ed.), Hong Kong history: New perspectives (Vol. 1, pp. 371-416). Hong Kong: Joint Publishing. 